\title{
OS CRUCEIROS DE CAPELA: IV. CONCELLO DE AMES
}

\author{
Por \\ CLODIO GONZÁLEZ PÉREZ
}

Proseguimos coa catalogación dos cruceiros de capela existentes en Galicia, centrándonos agora no concello de Ames. Xa foron publicados os de Rois, Ribeira e Brión ${ }^{1}$. Debido a súa situación xeográfica, é o que queda máis cara ó interior de todos aqueles onde hai este tipo de cruceiros.

Como vimos repitindo nos artigos que lle levamos dedicado a estes interesantes monumentos populares, o día que rematemos a súa catalogación, será entón o momento de proceder a facer un traballo de síntese, xa que nos permitirá xulgar tódolos exemplares en conxunto, e non só por concellos, divisións administrativas relativamente recentes que en nada están vencellados con eles.

\section{CRUCEIROS DO CONCELLO DE AMES}

O territorio deste concello pertence na súa maioría á comarca natural da Amaía, relacionada dende o propio intre en que se descubriron os supostos restos do apóstolo Santiago coa igrexa compostelana. Pertenceu

\footnotetext{
${ }^{1}$ C. GONZÁLEZ PÉREZ: «Os cruceiros de capela. I. Concello de Rois»; «Os cruceiros de capela. II. Concello de Santa Uxía da Ribeira», «Os cruceiros de capela. III. Concello de Brión», Cuadernos de Estudios Gallegos, núms. 103 (1989), 104 (1990), 105 (1992) e 107 (1995).
}

"CUADERNOS DE ESTUDIOS GALLEGOS", Tomo XLIII, Fascículo 108, Santiago 1996. 
á provincia de Santiago de Compostela, e dentro dela, as parroquias repartíanse entre as xurisdiccións de Altamira (Agrón, Bugallido, Lens, Ortoño e Trasmonte), A Amaía (Ames e Covas), Xiro da Rocha (Ameixenda e Biduído), e Dubra (Piñeiro e Tapia).

Linda cos concellos de Santiago de Compostela, Teo, Brión, Negreira, A Baña e o Val do Dubra, e ten unha extensión territorial de $80,9 \mathrm{~km}^{2}$. Aínda que leva a denominación da parroquia de Santo Tomé de Ames, o núcleo urbano máis importante é do de Bertamiráns —onde se acha a casa consistorial—, situado na estrada de Santiago de Compostela a Noia, pertencente á freguesía de Ortoño. O outro núcleo que tamén sobresae é o do Milladoiro, na estrada de Santiago de Compostela a Pontevedra, que polo relixioso vén a ser de Biduído (Lám. I).

En Ames existen exemplares dos dous tipos tradicionais de cruceiros: de varal e de capela. Os primeiros son os predominantes, pois en todo o concello só hai un dos segundos. Algúns dos de varal redúcense a sinxelas cruces, sen ningunha representación iconográfica. Os veciños maiores seguen respectando estes monumentos, devoción herdada dos seus devanceiros.

Os máis deles atópanse en encrucilladas ou ó longo dos camiños «sacramentais», é dicir, de aqueles por onde tiñan que pasar cos defuntos ata a igrexa parroquial, e logo ó cemiterio. Isto é xeral para toda Galicia, pois tanto os cruces de camiños, como aqueles por onde se levaban os mortos, sempre se consideraron vencellados coa morte, cos veciños que xa dormen o sono eterno, pero que podían voltar xunto ós familiares ou amigos a solicitar responsos, misas, actos fúnebres, etc., para así acadar a gloria eterna.

\section{CRUCEIROS DE CAPELA DE AMES}

Actualmente non existe máis que un, pero de excelente factura, digno de figurar en calquera dos estudios que se fagan sobre estas obras. Como adoita pasar nos demais concellos, os veciños non fan distingos entre as dúas clases, sendo «cruceiros» sen máis.

Entre todos salienta pola súa monumentalidade e antigüidade o que se ergue no adro da capela da Nosa Señora da Barouta, máis coñecida pola capela de San Amaro, por se venerar nela este santo que goza de grande

"CUADERNOS DE ESTUDIOS GALLEGOS", Tomo XLIII, Fascículo 108, Santiago 1996. 


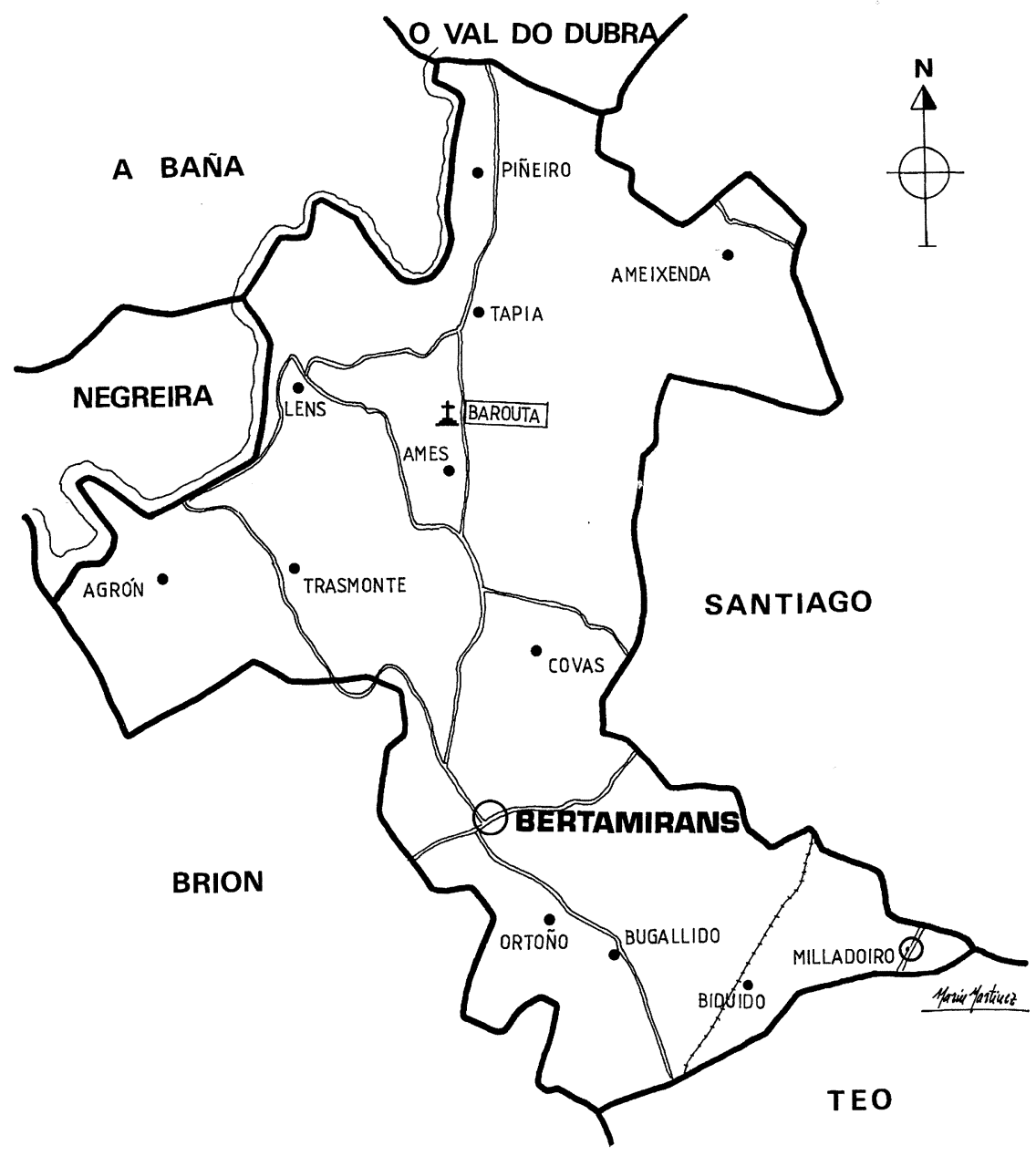

Lám. I. Concello de Ames: cruceiro da Barouta. 
devoción popular en toda a zona e, en particular, nas terras da Amaía. Ademais é este o único de capela, que coidamos que sexa o que se acha máis cara ó interior, pois hai a idea - aínda non desaparecida de todode que se trata de obras típicas e exclusivas das terras ribeirás².

O interesante e amplo edificio data dos últimos anos do século XVIII, en que foi totalmente reformado, segundo se deduce da seguinte nota que figura no Libro de Fábrica da igrexa parroquial de Santo Tomé de Ames:

Capilla de Ntra. Sra. de Barouta y San Mauro que dista mui poco de la Parroquial Iglesia y está al lado Norte de ella en una bajada trecho y camino mui a propósito para Procesiones desde dha. Parroquia a la referida Capilla [...] Comunmente conocida con el nombre de S. Mauro está fabricada recientemente a cimentis, y es de iladas de cantería por la parte interna y externa con su cornisa y fachada [...] por su buena fábrica podrá muy bien servir para una iglesia parroquial ${ }^{3}$.

Entre as tallas que se atopan no seu interior, destaca a de San Amaro, datable entre 1760/70, que poidera ser obra do imaxineiro Bieito Silveira, ou do seu círculo artístico. Tampouco son despreciables as de San Antón Abade acompañado - como é tradicional- do seu porquiño, a de San Xosé e a de San Domingos de Guzmán. O retábulo é neoplateresco.

A actual obra sustitueu a outra anterior, xa que o cruceiro é cronoloxicamente anterior. En 1607 di o cardeal e cóengo de Santiago de Compostela Jerónimo del Hoyo, ó tratar da parroquia de Ames: Hay una hermita de Nuestra Señora y de San Amaro 4 .

A Barouta debeu ser en tempos pasados unha aldea de certa importancia, pois a mediados do século XVIII - ano 1753-, xa había unha taberna: otra de Sn. Amaro de Barouta 5 .

\footnotetext{
${ }^{2}$ Esta errada opinión débese a Castelao, que só estudiou algúns dos existentes na costa, chegando a dicir que dende Rianxo a Noia, seguindo a veira do mar, hai unha chea de cruceiros con grosa colúa e unha capeliña en lugar do capitel (As cruces de pedra na Galiza, Buenos Aires, 1949-50, p. 175).

${ }^{3}$ Ano 1791, folio 3 .

${ }^{4}$ Memorias del Arzobispado de Santiago, edición de A. Rodríguez e B. Varela, Santiago de Compostela, s.a., p. 195.

${ }^{5}$ Catastro de La Ensenada: Ynterrogatorio de la feligresía de Sn. Tomé de Ames, y otras, libro 250, folio 429, Archivo General de Simancas.
}

"CUADERNOS DE ESTUDIOS GALLEGOS", Tomo XLIII, Fascículo 108, Santiago 1996. 


\section{CRUCEIRO DE SAN AMARO DA BAROUTA}

\section{Situación}

Atópase no campo da festa da capela de San Amaro. No amplo adro sombreado por abundantes árbores, que antes tamén facía de patio de recreo dos alumnos dunha escola que construíron fronte ó cruceiro os veciños emigrantes en Arxentina: Sociedad pro-escuela residentes de Ames en Buenos Aires, 1936 (Lám. II).

\section{Descripción}

O basamento está formado por tres chanzos, de maior a menor, facendo como sempre o máis pequeno de basa, no que se afinca o fuste, formado por unha única pedra, de boa altura, pois mide $1,65 \mathrm{cms}$. É de sección cadrada (de 30 por $30 \mathrm{cms}$.), coas arestas rebaixadas dende pouco despois do comezo ata tamén uns centímetros antes de rematar.

No fronte do fuste hai esculpida unha figura en relevo, que ten por enriba unha especie de dosel semicircular que lle vai de ombro a ombro. Trátase de San Xoán Bautista: o santo viste só con unha pelica que lle cai por detrás, deixándolle as pernas descubertas dende máis arriba dos xionllos. No lado esquerdo ten un año incoporado sobre as patas traseiras, que apoia as de adiante sobre o Santo, chegando ata a altura da cintura. A man esquerda pónlla sobre o lombo, mentres que coa dereita tócalle no fociño. Trátase de unha labra moi sinxela, de escaso valor artístico, na que case non se distinguen os rasgos anatómicos (Lám. III).

Segue o capitel, de feitura tradicional estes cruceiros, moi voluminoso, de catro lados lisos, pois de non ser así non podería soster a capela sobre el. No fronte ten esculpido en baixorrelevo unha cara de anxo con ás, que non só ten lateralmente, senón que tamén por debaixo. A diferencia dos demais que coñecemos, no lado dereito conta con unha especie de círculo e dentro del, en baixorrelevo case imperceptible, dúas figuras moi borrosas, das que non hai dúbida que a superior ten na man dereita unha espada. Por debaixo distínguese outra con grandes cabelos. Seguro que representa a decapitación de San Xoán Bautista, levada a termo por orde de Herodes (San Mateu, 14, 9).

A capela é unha construcción moi esvelta, formada por catro pedras máis a que fai de base: dúas laterais, unha por detrás, e outra que cubre o conxunto, a xeito de teito de catro augas. $\mathrm{O}$ interior da fornela é totalmente liso. Dentro acóllese unha imaxe da Virxe co Neno Xesús no colo sobre o lado esquerdo. 


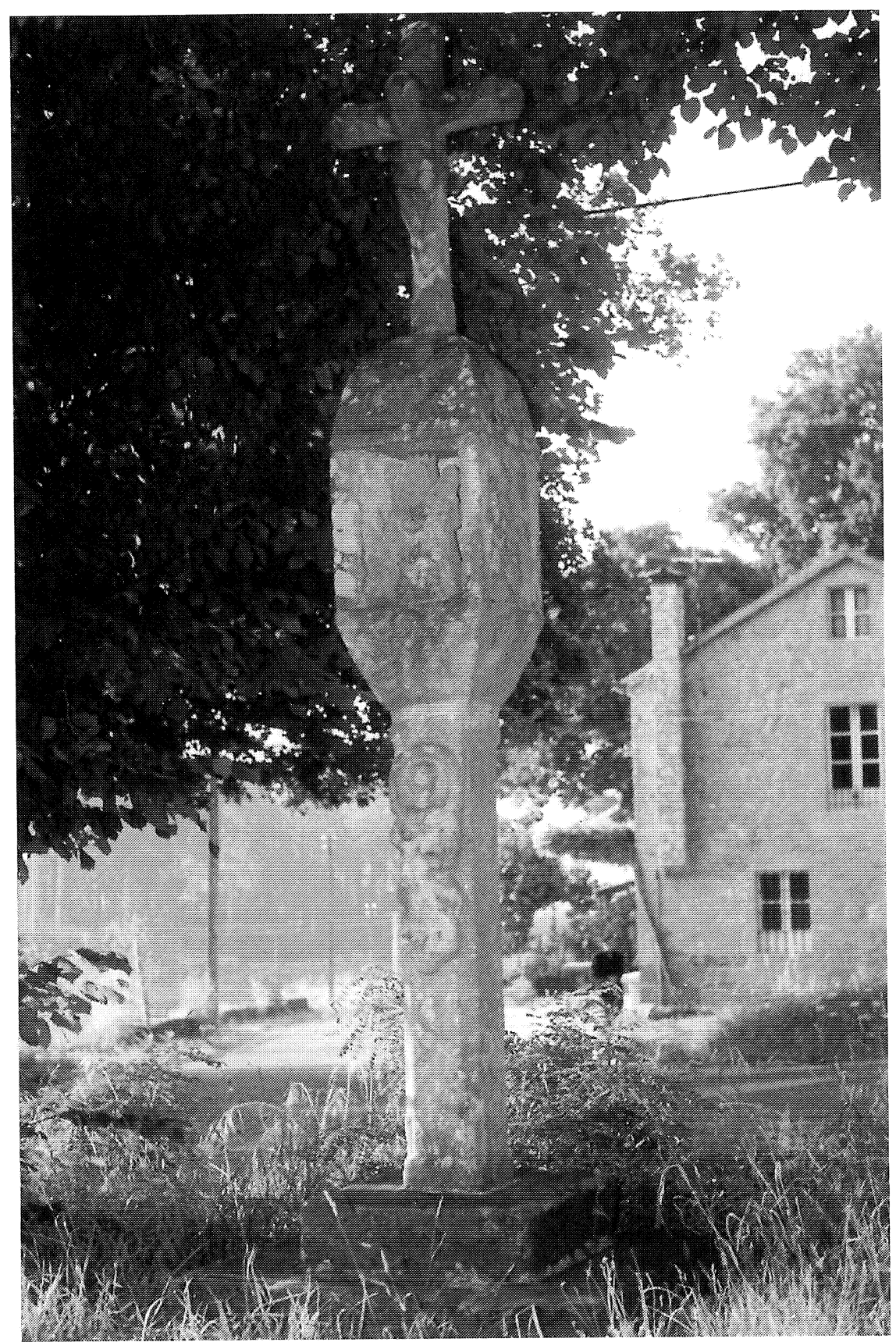

Lám. II. Cruceiro de San Amaro da Barouta. 


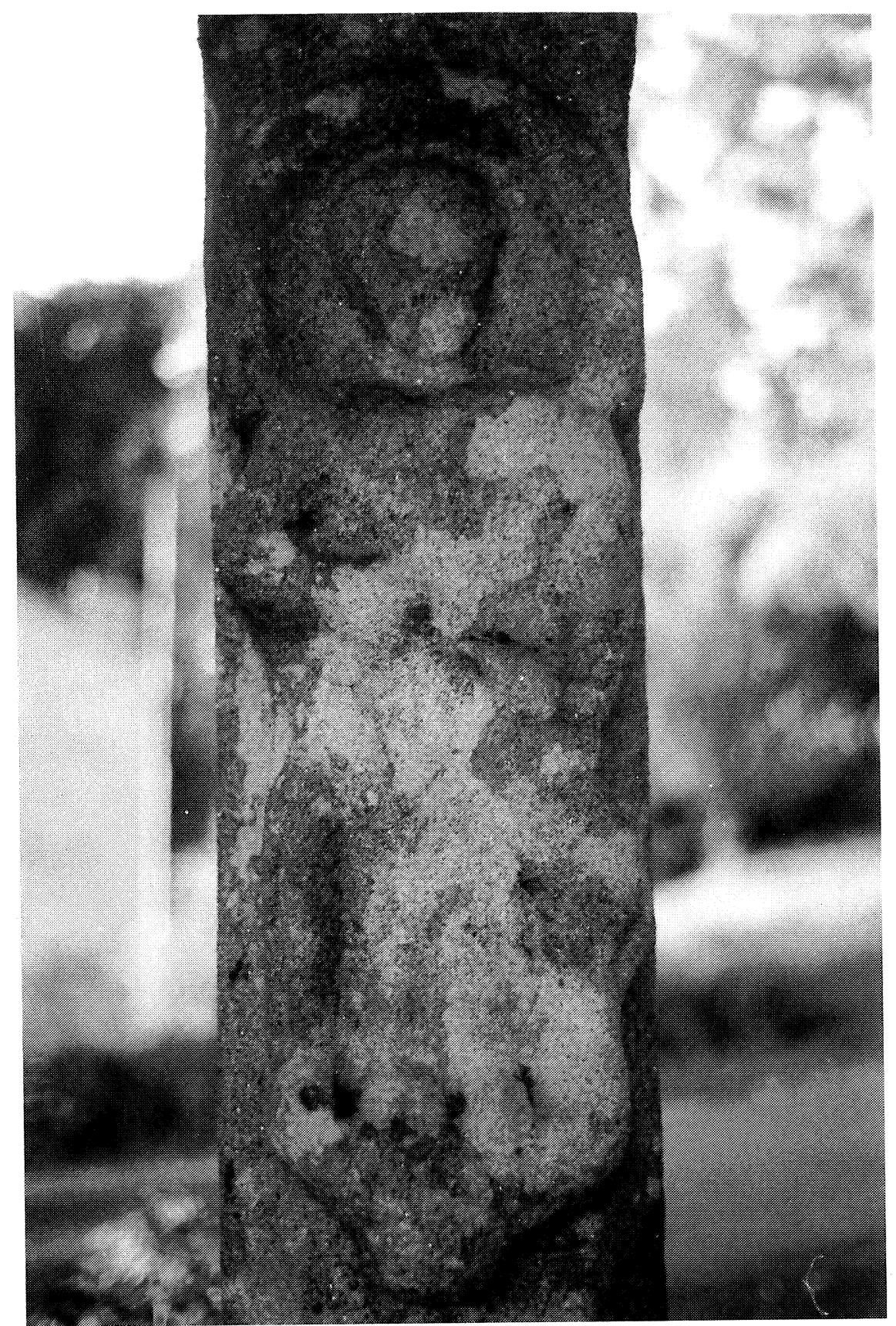

Lám. III. Cruceiro da Barouta: San Xoán Bautista. 
A Nai amósase cariñosa, parecendo que lle sonrrí ó fillo, mentres que coa man dereita xoga cos dedos do pé dereito do neno. A roupa da nai é moi sinxela, aínda que se distinguen pregamentos, pola contra, o neno está espido. A Virxe porta coroa con puntas ben marcadas. As faccións do rostro case non se aprecian, por atoparse toda a labra moi desgastada pola pouca consistencia da pedra (Lám. IV).

A cruz é alta, quizais das máis que coñecemos. De sección cadrada coas arestas rebaixadas. Nos cantos ten un círculo concéntrico a un punto, motivo que tamén se repite noutros exemplares.

A anatomía da figura é regular, destacando ben os pectorais. O pano de pureza conta con dous nós, un a cada lado, polo que a súa forma é redondeada por diante. O que si destaca é a coroa de espiñas, apoiada sobre o longo cabelo que lle chega ate os ombreiros. A cabeza tena algo revirada cara ó lado dereito. Está suxeito á cruz por tres cravos.

Por detrás da cabeza, tamén como é tradicional nestes cruceiros, hai un pequeno nimbo circular, e, sobre el, para rematar o conxunto, a cartela apergamiñada do INRI.

A esvelteza desta obra amósase pola súa altura, que dende o chan aproxímase ós cinco metros (sobre 4,80 m.).

\section{Historia}

Por carecer de inscripción, hai que deducir a súa data de construcción comparándoo con outros semellantes, e mellor se son próximos. No concello de Ames el é o único de capela, o que obriga a procurar exemplares fóra, nos lindeiros de Brión e Rois.

Atendendo ás súas características, case seguro que é obra da segunda metade do século XVII. E ata hai a posibilidade que se deba ó mesmo artista ou taller que labrou o Da Goriña, situado na aldea de Pousada (Viceso, Brión), que vén a ser un dos que queda máis preto, despois dos dous de Vioxo (A Luaña).

O Da Goriña está datado: foi labrado o ano 1673. O da Barouta coidamos que sexa contemporáneo, poucos anos arriba ou abaixo ${ }^{6}$.

${ }^{6}$ Cfr. C. GONZÁLEZ PÉREZ: «Os cruceiros de capela: III. Concello de Brión», Cuadernos de Estudios Gallegos, núm. 107, 1995, pp. 487 e ss.

"CUADERNOS DE ESTUDIOS GALLEGOS", Tomo XLIII, Fascículo 108, Santiago 1996. 


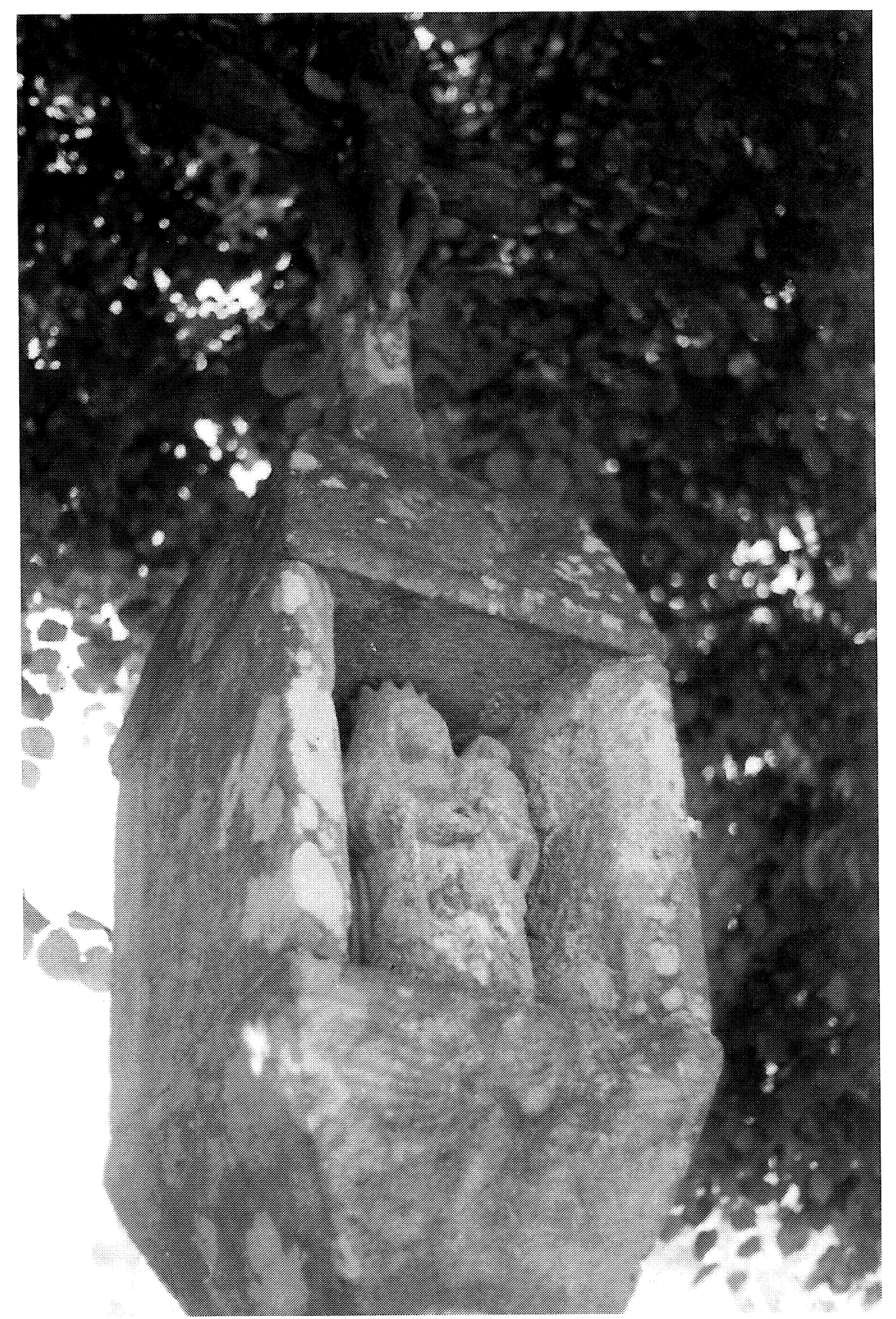

Lám. IV. Cruceiro da Barouta: capela. 
Gende Franqueira, que fixo un concienzudo estudo sobre a arte relixiosa do arciprestado da Amaía, anque non adoita pararse cos cruceiros, no caso en particular do da Barouta dedicoulle varias liñas. Sobre a datación de este e do de Carrais (Herbogo, Rois), escribe: Son difíciles de datar, dada la persistencia de tipos en la escultura popular, pero pudieron corresponder a fines del siglo XVI.

Non concordamos con esta data, atendendo a exemplares semellantes da mesma época. Respecto á orixe deste tipo de cruceiros, Gende Franqueira segue a Castelao, que opinaba que se ergueron coa fin de implorar a protección da Virxe de Loreto contra os piratas que asolaban as costas. Aínda que non é este o caso do noso - como de outros moitos máis-, por atoparse tan lonxe do mar. Para os veciños da Barouta é, sen máis, a Virxe ${ }^{8}$.

Foi restaurado non hai moito, encintándolle as unións das pedras con cemento, ó tempo que procedían a súa limpeza, o que orixinou a perda da pátina antiga, danando considerablemente a parte escultórica.

\section{Tradicións}

Non destaca neste aspecto, cinguíndose ás dos cruceiros normais, como a de deterse antano as comitivas fúnebres cando pasaban de par cara á igrexa parroquial. Arredor del vira a procesión do San Amaro o día da súa festa.

\section{CONCLUSIÓNS}

Pouco se pode dicir de unha soa obra. Soamente que este cruceiro de San Amaro da Barouta é o que queda máis no interior, a curta distancia da liña divisoria de Ames e Santiago de Compostela.

Como sucede noutros concellos (poñamos por caso o lindeiro de Brión), é o máis antigo de todos cantos se conservan actualmente no de Ames, aínda que dende antes se rexistren algúns de varal. Tal é o caso de un que agora non se conserva que se ergueu preto da igrexa de Trasmonte, xa

${ }^{7}$ El Arte religioso en la Mahía, Madrid, 1981, p. 188. Sobre o de Carrais, C. GONZÁLEZ PÉREZ: «Os cruceiros de capela: I. Concello de Rois», Cuadernos de Estudios Gallegos, núm. 103, 1989, pp. 373 ss.

${ }^{8}$ CASTELAO: Obr. cit., p. 97.

"CUADERNOS DE ESTUDIOS GALLEGOS", Tomo XLIII, Fascículo 108, Santiago 1996. 
antes de 1616, como se deduce do contrato asinado entre Xoán Fernández, mestre canteiro compostelán, e Alonso de Lema, veciño de San Pedro de Verdoias (Vimianzo), para que o primeiro labrase un para poñer diante do convento de San Lourenzo de Trasouto (Santiago), o día 14 de decembro de 1616, facéndose constar que sexa de piedra de grano bueno [...] de la figura, altor y modelo y ymáxenes conforme al crucero que está viniendo de la puente Maceira para Aguapesada, que está junto a la iglesia de Santa María de Trasmonte ${ }^{9}$.

\section{BIBLIOGRAFÍA}

\section{a) Fontes documentais}

Arquivo da catedral de Santiago de Compostela: Colección de documentos soltos, núm. 364 (14-decembro-1616).

Libro de Fábrica, parroquia de Santo Tomé de Ames, ano 1791.

\section{b) Publicacións}

CASTELAO: As cruces de pedra na Galiza, Buenos Aires, 1949-50.

GENDE FRANQUEIRA, G.: El arte religioso en la Mahía, Fundación Universitaria Española, Madrid, 1981.

GONZÁLEZ PÉREZ, C.: «Os cruceiros de capela. I. Concello de Rois», Cuadernos de Estudios Gallegos, 103 (1989) e 104 (1991).

GONZÁLEZ PÉREZ, C.: «Os cruceiros de capela. II. Concello de Santa Uxía da Ribeira», Cuadernos de Estudios Gallegos, 105 (1992).

GONZÁLEZ PÉREZ, C.: «Los cruceros de capillita», Revista de Folklore, núm. 155, Valladolid, 1993.

GONZÁLEZ PÉREZ, C.: «Os cruceiros de capela: III. Concello de Brión», Cuadernos de Estudios Gallegos, 107 (1995).

\footnotetext{
${ }^{9}$ Arquivo da catedral de Santiago de Compostela: «Colección de documentos soltos», núm. 364. Tamén P. PÉREZ COSTANTI: Diccionario de artistas que florecieron en Galicia durante los siglos XVI y XVII, Santiago de Compostela, 1930, p. 186.
}

"CUADERNOS DE ESTUDIOS GALLEGOS", Tomo XLIII, Fascículo 108, Santiago 1996 